\title{
Estimating default correlations using simulated asset values
}

\author{
Osei Antwi ${ }^{1,}$, , Dadzie Joseph ${ }^{1}$, Louis Appiah Gyekye ${ }^{2}$ \\ ${ }^{1}$ Mathematics and Statistics Department, Accra Polytechnic, Accra, Ghana \\ ${ }^{2}$ Research \& Innovations Center, Accra Polytechnic, Accra, Ghana
}

Email address:

oseiantwi@yahoo.com (O.Antwi), kobenagyesi@yahoo.com (O. Antwi), kwabenaappiahokubi@gmail.com (O. Antwi)

\section{To cite this article:}

Osei Antwi, Dadzie Joseph, Louis Appiah Gyekye. Estimating Default Correlations Using Simulated Asset Values. Science Journal of Applied Mathematics and Statistics. Vol. 3, No. 1, 2015, pp. 14-21.doi: 10.11648/j.sjams.20150301.13

\begin{abstract}
We outline the ingredients necessary to compute the Joint Default Probability from which we obtain Default Correlation, an important risk quantity in the determination of Internal Rating Based Approach in Basel II and III documents on banking supervision and regulations. We discuss Merton's structural approach of which one key drawback is the difficulty in tracking and calibrating asset value processes and the limitations of variant models which tend to be analytically too complex and computationally intensive. We address these issues by simulating all the possible asset value processes of a firm whose asset paths we assume to be Gaussian. By generating random values that simulate all the possible asset value processes, we are able to capture all the possible default horizons within a certain macroeconomic framework. Drawing standardised normally distributed assets values of obligors we obtain a range of values of Joint Default Probabilities at a specified asset correlation from which the corresponding range of default correlations are obtained. The results is a simplified approach to the determination of default correlation, easily implementable in Excel and less analytically complicated than existing procedures.
\end{abstract}

Keywords: Obligor, Probability of Default, Joint Default Probability, Asset Correlation, Default Threshold, Default Correlation

\section{Introduction}

The recent crisis in credit markets that led to the collapse of several financial institutions and resulted in huge losses to major financial markets, leading to what has become infamously known as the credit crunch has given cause for improved credit risk management within financial institutions throughout the world. Credit risk, commonly defined as the loss resulting from failure of obligors to honour their payments has recently become a dominant source of risk component for banks, and is now a subject of strict regulatory oversight and policy debate [1]. In order to improve on credit risk management many financial institutions may have moved or are about to move towards Internal Ratings Based (IRB) Approach as regards risk management and supervision. However, the most important step in switching towards IRB Approach (whether Foundation or Advanced), is to determine as accurately as possible, the Probability of Default (PD) for a certain portfolio of credit instruments.

Regulatory bodies are not the only institutions interested in the properties of probability of default estimates. PD's are also inputs to the pricing of credit assets; bonds and loans to more sophisticated instruments such as credit derivatives. In addition, PD's also forms a core part in allocation of capital, client judgment, regulatory compliance and finally better monitoring of high risk customers. Due to these significant reasons, financial institutions must ensure that the probability of default determination is sophisticated and more importantly, show the true picture of a portfolio in present as well as future scenarios. Although individual probability of default is important the issue of two or more obligors defaulting together has risen to become a subject of great concern in credit risk modeling and regulation due to the massive defaults that characterised the major economies during the crunch.

For a financial institution that wants to assess the default risk of its loan portfolio, individual default probabilities are not enough. Consider the simplest case in which a portfolio comprises of only two obligors/borrowers, and the bank would like to know the probability that both obligors default in the next period. This cannot be measured with default probabilities alone. If we assume that the two borrowers are 
independent then the probability that both of them default would then equal the product of the two individual default probabilities. However this is not always the case, default rates of firms fluctuate with macroeconomic or industryspecific conditions, so we cannot rely on defaults being independent. What we need to know in this case is the default correlation.

The default correlation gives an indication of the tendency of two loans to default at the same point in time. Default correlation is very important in understanding and predicting the behaviour of credit portfolios. It directly affects the riskreturn profile of investors in credit risk assets and is one of the most pervasive threats in financial markets and therefore very important to creditors and regulators. Accurate measurement of default correlation is therefore crucial especially in credit risk portfolio management and to credit investors such as banks making loans to individuals and corporations or fixed income managers allocating assets in the credit markets.

Currently, in modeling credit risk, two classes of models exist: Structural and Reduced form models. Structural models originated with [2,3] and reduced form models originated with [4], and subsequently studied by [5, 6] among others. These models are viewed as competing (see $[7,8,9,10]$ ), and there is a heated debate in the professional and academic literature as to which class of models is best [11].

Structural models started with Merton (1974) in which the default of a firm is based on its asset value and its liabilities. If the assets value of the firm fall below its liabilities a default is triggered. The Merton model thus relies on the assumption that default is triggered by the value of the assets, therefore, the starting point is to set the diffusion process of the assets. The key postulate emphasized in the abstract form of the Merton's model is that the information set $\left\{G_{t}: t \in[0,1]\right\}$ that the modeler observes contains the filtration generated by the firm's asset value. Let the firm's asset value be denoted by $V_{t}$. Then, the filtration

$$
F_{t}=\sigma\left(V_{s}: s \leq t\right) \subset G_{t}
$$

Let the firm's asset value follow a diffusion process that remains non-negative, then the value of the assets is governed by the Geometric Brownian Motion process and can be shown as:

$$
d V_{t}=V_{t}(r-\delta) d t+\sigma d W_{t}
$$

where $\delta$ is the drift of the asset return, and $\sigma$ is the volatility of the asset returns, suitably chosen so that the expression is well defined and the initial value of the assets $V_{0}>0$. The process $W_{t}$ is a standard Brownian motion under the (risk-neutral) martingale measure Q. The firm issues a single class of debt, a zero-coupon bond, with a face value $B$ payable at $T$. Default may happen only at date $T$, and if default happens, creditors take over the firm without incurring any distress costs and realize an amount $V_{t}$. Otherwise, they receive $F$. In short, the payoff to the creditors at date $T$ is a call option

$$
D\left(V_{t}, T\right)=\min \left(V_{t}, B\right)=B-\left(B-V_{t}\right)^{+}
$$

The representation of the payoff to creditors makes it clear that the creditors are sold a put option written on the assets of the borrowing firm with a strike price equal to $B$, the face value of debt. In addition, once we recognize that the borrower (equity holders in Merton's model), (a) owns the firm, (b) borrowed the amount $B$ at $t=0$, and (c) owns a put option on the assets of the firm with a strike price equal to $B$. It is immediate, by a put-call parity relationship, that equity is a call option on the assets of the borrowing firm with a strike price equal to $B$, the face value of debt. We can therefore express, respectively, debt and equity values as follows:

$$
\begin{gathered}
D\left(V_{t}, t\right)=P(t-T)-P u t_{B S}\left(V_{t}, B, r, T-t, \sigma\right) \\
E\left(V_{t}, t\right)=\operatorname{Call}_{B S}\left(V_{t}, B, r, T-t, \sigma\right)
\end{gathered}
$$

Merton's insight makes it clear that the spread between credit-risky debt and an otherwise identical risk-free debt is simply the value of this put option. Define $\tau=T-t$ and $N$ as the standard Gaussian cumulative distribution function given by:

$$
N(x)=\frac{1}{2 \pi} \int_{\infty}^{x} e^{-\frac{y^{2}}{2}} d y
$$

Then the corporate debt value is

$$
D(t-T)=V_{t} e^{-\delta(T-t)} N\left(-d_{1}\right)+B P(t-T) N\left(d_{2}\right)
$$

Where

$$
d_{1}=\frac{\operatorname{In}\left(\frac{V_{t}}{B}\right)+\left(r-\delta+\frac{1}{2} \sigma^{2}\right)(T-t)}{\sigma \sqrt{T-t}}
$$

and

$$
d_{2}=d_{1}-\sigma \sqrt{T-t}
$$

This is the original risky debt model of Black and Scholes (1973) and Merton (1974), where the firm's equity is viewed as a European call option on the firm's assets with maturity $T$ and a strike price equal to the face value of the debt.

Because the Black-Scholes and Merton model has default only occurring on one date, the model has since been generalized to allow default prior to time $T$ if the asset's value hits some pre-specified default barrier, $L_{t}$. The economic interpretation is that the default barrier represents some debt covenant violation. In this formulation, the barrier itself could be a stochastic process. Then, the information set must be augmented to include this process as well, i.e. $F_{t}=\sigma\left(V_{s}, L_{s}: s \leq t\right)$.

We assume that in the event of default, the debt holders 
receive the value of the barrier at time $T$. In this generalization, the default time becomes a random variable and it corresponds to the first hitting time of the barrier [12]:

$$
\tau=\inf \left\{t>0: V_{t} \leq L_{t}\right\}
$$

Other formulations of Merton's model are possible and the model has been refined in several forms.

The real beauty of Merton's model lies in the intuition of treating a company's equity as a call option on its assets, thus allowing for applications of Black-Scholes option pricing methods. Structural models are particularly useful for practitioners in the credit portfolio and credit risk management fields. The intuitive economic interpretation of the model facilitates consistent discussion regarding a variety of credit risk exposures. Corporate transaction analysis is also possible with the structural model. If an analyst wants to understand the impact on credit quality of increased borrowing, share repurchases, or the acquisition of another firm, the structural model naturally lends itself to understanding the transaction's implications. In general, the ability to diagnose the input and output of the structural model in terms of understandable economic variables (e.g. asset volatility as a proxy for business risk, the market's assessment of an enterprise's value, and the market leverage) facilitates better communication among loan originators, credit analysts, and credit portfolio managers [13].

Reduced-Form (RF) models of credit risk on the otherhand assume default is not directly based on firm's cash flows or values, but estimate a jump rate (intensity) to default empirically and are thus mostly useful in estimating credit spreads and default probabilities. Reduced form models do not consider endogenous cause of defaults; rather, they rely on exogenous specifications for credit default and debt recovery. This feature is both a strength and a weaknesswhile these models suffer from the lack of economic insights about default occurrence; they offer more degrees of freedom in functional form selection. Such flexibility contributes to analytical tractability and ease of implementation and calibration (compared to structural models). However, RF models dependence as shown in [14] relies on historical data which may result in good in-sample fitting properties but limited on out-of-sample predictive power.

In the RF model, a firm's default time is assumed inaccessible or unpredictable and driven by a default intensity that is a function of latent state variables. [5,6] present detailed explanations of several well known reducedform modeling approaches. Many practitioners in the credit trading arena have tended to gravitate toward this modeling approach given its mathematical tractability. [13] argues further that RF models are more appropriate in an information theoretic context given that we are unlikely to have complete information about the default point and expected recovery. Strictly speaking, most structural models assume complete information. [13] claim rests on the premise that a modeler only has as much information as the market, making the reduced-form approach more realistic. In practice, however, the complete information assumption in structural models is an approximation designed to facilitate a simpler way of capturing the various economic nuances of how a firm operates. The strength or weakness of a model should be evaluated on its usefulness in real world applications. A reduced-form model, while not compromising on the theoretical issue of complete information, suffers from other weaknesses including lack of clear economic rationale for defining the nature of the default process.

The approach in this paper is to estimate the default correlation based on structural models, specifically, the one factor model. The one factor model assumes that a single factor common to all counterparties influences the economic fortunes of the obligors in a portfolio and that the asset correlation between obligors is uniform. The one factor model, although not ideal under certain circumstances has the advantage of reducing the computational effort regarding the calculation of correlated defaults. Also, all the underlying factors influencing the firm are considered as a single factor making the model simple to use. In factor models, we make the assumption that default can only occur at maturity. This assumption ignores credit migration. Estimating defaults based on Merton's structured model is widespread in credit risk modeling and while many alternative models of measuring correlated default risk have been developed in literature, there is surprisingly little work on simulation of asset values to estimate default correlations. [15] evaluated default correlations utilising a particular theoretical structure of the default process. [16] estimated default correlations in a Bernoulli mixture model using single and multi group cases. Besides, [17] measured the average default correlations in various sectors of the US economy from 1981 to 1999 using methods of parameterization. [18] estimated default correlations using methods of moments and maximum likelihood approaches. [19] derived obligor default correlations by calculating the correlation matrix of the credit risk drivers and allowing the bivariate distributions to follow different kinds of distributions. Morten also studied actual default rates in the USA from 1920-2008 and concluded that obligors tend to default together which indicates that obligors are subject to the same underlying risk drivers i.e. economic variables.

One drawback of Merton's model to estimate default correlations lies in the simplicity of the model in applying the Black and Scholes formula to value firm's equity and debt. This comes at the cost of too simplistic assumptions regarding the asset value process, interest rate, and the capital structure. Another key disadvantage of these models lies in the difficulty of tracking and calibrating asset processes using publicly available information. Furthermore, although improved structural models have addressed several limitations of earlier models, they tend to be analytically complex and computationally intensive. In this paper, we give an alternate approach to solving this problem by simulating all the possible asset value scenarios of the firm. To do this we consider a portfolio of two obligors and assume that their possible asset value paths are Gaussian. By 
generating random values that simulate all the possible asset value processes, we are in a position to capture all the possible default horizons within a certain macroeconomic framework. We proceed to determine the Joint Default Probability and subsequently the Default Correlation. The approach here is simple to implement in Excel and does not require rigorous mathematical formulations that characterises most of the approaches to determine default correlation.

\section{Methodology}

We will begin by explaining the various components of credit risk.

\subsection{Default of an Obligor}

There are various definitions of default. Throughout the text we shall refer to default as failure to pay promptly interest or principal on a loan agreement when due i.e. payment default. Basically, there are two methods of measuring losses due to credit risk. These are mark-to-market method and default method. The mark-to-market paradigm recognises losses when the credit quality of the obligor (also referred to as debtor), is an entity that has an obligation to pay all principal and interest on a debt deteriorates, i.e. migrates to a lower credit rating. Such losses are not paid out, but only recognised when the portfolio of the bank is marked-to-market. Credit migration is the approach used by JP Morgan Chase Bank. Throughout the text we shall focus on defaults only and ignore the defaults related to credit migration.

\subsection{Default Correlation of Two Loans}

In this paper, we will examine a widely used way of modeling, the so called asset value approach. The standard definition of the correlation coefficient of two random variables $X_{1}$ and $X_{2}$ :

$$
\rho_{x_{1} x_{2}}=\frac{\operatorname{cov}\left(X_{1}, X_{2}\right)}{\sigma\left(X_{1}\right) \sigma\left(X_{2}\right)}
$$

Where cov denotes the covariance, and $\sigma$ the standard deviation. In our case, the random variable is a default indicator $y_{i}$ that takes the value 1 if obligor $i$ defaults or 0 otherwise. Thus, the default correlation we are searching is therefore:

$$
\rho_{i j}=\frac{\operatorname{cov}\left(y_{i}, y_{j}\right)}{\sigma\left(y_{i}\right) \sigma\left(y_{j}\right)}
$$

Inserting our notation into the standard definition of variance leads to:

$$
\begin{aligned}
\sigma^{2}\left(y_{i}\right)= & \operatorname{Prob}\left(y_{i}=1\right)\left(1-E\left(y_{i}\right)\right)^{2} \\
& +\operatorname{Prob}(y=0)\left(0-E\left(y_{i}\right)\right)^{2}
\end{aligned}
$$

Denoting the default probability Prob $\left(y_{i}=1\right)$ by $P_{i}$ and exploiting the fact that $\operatorname{Prob}\left(y_{i}=1\right)$ is the same as $E\left(y_{i}\right)$ we get:

$$
\begin{aligned}
\sigma^{2}\left(y_{i}\right) & =p_{i}\left(1-p_{i}\right)^{2}+\left(1-p_{i}\right)\left(0-p_{i}\right)^{2} \\
& =p_{i}\left(1-p_{i}\right)^{2}+p_{i}^{2}\left(1-p_{i}\right) \\
& =p_{i}\left(1-p_{i}\right)
\end{aligned}
$$

Which is the familiar result for the variance of a Bernoulli variable with success probability $P_{i}$.

To express the covariance in terms of default probabilities we utilise the general result

$$
E\left(X_{1} X_{2}\right)=E\left(X_{1}\right) E\left(X_{2}\right)+\operatorname{cov}\left(X_{1}, X_{2}\right)
$$

In our case, this implies:

$$
\begin{aligned}
\operatorname{cov}\left(y_{i}, y_{j}\right) & =E\left(y_{i} y_{j}\right)-E\left(y_{i}\right) E\left(y_{j}\right) \\
& =p_{i j}-p_{i} p_{j}
\end{aligned}
$$

Where $\rho_{i j}$ denotes the joint default probability $\operatorname{Pr} o b\left(y_{i}=1, y_{j}=1\right)$ [19].

Thus, the default correlation is completely specified by the individual $P_{i} s$ and the joint default probabilities:

$$
\rho_{i j}=\frac{p_{i j}-p_{i} p_{j}}{\sqrt{p_{i}\left(1-p_{i}\right) \times p_{j}\left(1-p_{j}\right)}}
$$

\subsection{Probability of Default (PD)}

The Probability of Default (PD) indicates the degree of likelihood or the probability that promised payments such as interest and coupon payments and principal repayments will not be paid by the obligor when due. The assignment of a default probability to every customer in a credit portfolio is far from an easy task. The pioneers of estimation of default probabilities are rating agencies like Moody's and S\&P. Today, other popular names of credit risk models are CreditMetrics (JP Morgan), CreditPortfolioView (McKinsey), PortfolioManager (KMV) and CreditRisk+ (Credit Suisse). They started to publish not only the ratings of companies but also their estimated default probabilities. These estimates are produced from historical data. Due to the limitations of historical data, models were developed which described real world activities via assumptions on explaining variables. The estimates are produced within the context of the underlying model. There are essentially two approaches to the assignment of probability of default: Calibration of default probabilities from market data developed by KMV corporation and Calibration of default probabilities from ratings where ratings are assigned to customers either by external rating agencies like Moody' Investors Services, Standard \& Poor (S\&P) or FITCH, or by a bank internal rating methodologies. Quantitative as well as qualitative information is used to evaluate the client. 


\subsection{Joint Default Probability}

The Joint Default Probability is the probability that two obligors default at the same time horizon. The Joint default probability gives us the frequency measure of how defaults of obligors occur together in a credit portfolio. As explained earlier, a one factor model incorporates the idea that every firm admits a process of asset values, such that default or survival of the firm depends on the state of the asset values at the planning period. An obligor defaults on its obligations as soon as the value of the obligor's assets falls below a certain threshold which is considered as a function of the value of the obligor's liabilities. The Joint Default Probability of the two obligors is the probability that the value of their assets drops below their liabilities simultaneously. At this stage, the asset value (i.e. the value of the firm) is not sufficient to cover the firm's liabilities. In effect the default of a firm is triggered by a decline in the firm's asset value. Let the firm's asset value at time $t$ be $V_{i}(t)$. For each firm $i$, there exist a time-dependent value $C_{i}(t)$ such that the firm continuous to operate and meets its contractual obligations as long as $V_{i}(t)>C_{i}(t)$. However, if $V_{i}(t)$ falls to the threshold level $C_{i}(t)$, the firm defaults on all its obligations immediately, and some form of corporate restructuring takes place. Following [20], we assume that the time dependence of $C_{i}(t)$ takes an exponential form

$$
C_{i}(t)=e^{\lambda_{i} t} k_{i}
$$

There are many interpretations of the default boundary $C_{i}(t)$. Black and Cox (1976) interpreted $C_{i}(t)$ as the minimum firm value required by the safety covenant of a debt contract. If the value of the firm falls to $C_{i}(t)$, its bond-holders are entitled to force the firm into bankruptcy and obtain ownership of the firm's assets. According to [20], $C_{i}(t)$ takes an exponential form in $t$ because the expected value usually takes this form. In many practical applications, $C_{i}(t)$ is set to a weighted average of the firm's long-term and short-term liabilities, and $\lambda_{i}$ can be interpreted as the growth rate of the firm's $i$ 's liabilities.

\subsection{Asset Correlation}

To determine the Joint Default Probability of the two obligors, we first need to calculate the Asset Correlation of the two obligors. Asset Correlation plays a principal role in determining probabilities of defaults within a portfolio. A lower asset correlation implies lower joint default probabilities. The financial concept of asset correlation is important as it allows the allocation of assets so as to diversify and lower the portfolio volatility. Combining asset categories that have a low correlation and subsequently low default correlations reduces the volatility of the portfolio as a whole.

The Merton (1974) framework allows the calculation of a host of default and survival probabilities for a portfolio of obligors. Let's represent defaults as a function of continuous variables and then impose structure on these variables. Let us name these variables $A_{i} i=1$ to $N$. The default indicator can be represented as:

$$
\begin{gathered}
\text { Default }_{i} \Leftrightarrow y_{i}=1 \Leftrightarrow A_{i} \leq d_{i} \\
\text { No } \text { Default }_{i} \Leftrightarrow y_{i}=0 \Leftrightarrow A_{i}>d_{i}
\end{gathered}
$$

Where $d_{i}$ is the critical value which marks the default of borrower $i$ if the variable $A_{i}$ falls below it.

The joint default probability between the obligors is

$$
\operatorname{Prob}\left(y_{i}=1, y_{j}=1\right)=\operatorname{Prob}\left(A_{i} \leq d_{i}, A_{j} \leq d_{j}\right)
$$

The variables $A_{i}$ are latent variables that determine an observed, discrete outcome. In the credit risk literature, the latent variables are usually interpreted as the firm's asset values. As explained in the literature, in the Merton's optiontheoretic approach, a firm defaults if its asset value falls below a critical threshold associated with the value of liabilities. The asset values are assumed to be normally distributed with correlations that go back to a single common factor. Formally, borrower $i^{\prime} s$ asset value $A_{i}$ depends on the common factor $Z$ and an idiosyncratic factor $\mathcal{E}$ :

$$
\begin{aligned}
& A_{i}=w Z+\sqrt{1-w^{2}{ }_{i} \varepsilon_{i}}, \\
& \operatorname{cov}\left(\varepsilon_{i}, \varepsilon_{j}\right)=0, \\
& i \neq j \operatorname{cov}\left(Z, \varepsilon_{i}\right)=0, \forall i
\end{aligned}
$$

where $Z$ and $\varepsilon_{i}$ are standard normal variables. By construction, $A_{i}$ is also standard normal. From 9, the asset correlation is completely determined by the factor sensitivities $w_{i}$ and $w_{j}$ (also called systematic factors) and is given by

$$
\begin{aligned}
\rho^{\text {asset }_{i, j}} & =\frac{\operatorname{cov}\left(A_{i}, A_{j}\right)}{\sigma\left(A_{i}\right) \sigma\left(A_{j}\right)} \\
& =\frac{\operatorname{cov}\left(w i Z+\sqrt{1-w^{2}} \varepsilon, w_{j} Z+\sqrt{1-w^{2}}{ }_{j} \varepsilon\right.}{1 \times 1} \\
& =\operatorname{cov}\left(w_{i} Z, w_{j} Z\right)=w_{i} w_{j} \operatorname{var}(Z)=w_{i} w_{j}
\end{aligned}
$$

The asset correlation between the two obligors is thus a function of their sensitivity to the volatility of the systematic factor.

The Joint Default Probability is a function of the $P D{ }^{\prime}$ of the obligors and their asset correlation. The probability of default of obligor $i$ denoted by $P_{i}$ is

$$
P_{i}=P_{i}\left(A_{i} \leq d_{i}\right)=\Phi\left(d_{i}\right)
$$


Where $\Phi\left(d_{i}\right)$ denotes the cumulative standard normal distribution function with correlation $\rho$. The Joint Default Probability is

$$
P_{i j}=P\left(A_{i} \leq d_{i}, A_{j} \leq d_{j}\right)=\Phi\left(d_{i}, d_{j}, \rho^{a s s e t_{i, j}}\right)
$$

Where $\Phi\left(d_{i}, d_{j}, \rho^{a s s e t_{i, j}}\right)$ denotes the bi-variate standard normal distribution function with asset correlation $\rho^{a^{a s s t_{i, j}}}[17]$.

We evaluate the $J D P$ by determining the volume under the asset value distribution up to the default threshold of the two obligors. Now let our obligors assume the designation obligor $i$ and obligor $j$, then mathematically, the $J D P$ is a double integral established by the Joint Probability Density function:

$$
\begin{aligned}
& \mathrm{f}(\mathrm{x}, \mathrm{y})= \\
& \iint_{-\infty} \frac{1}{2 \pi \sigma_{i} \sigma_{j} \sqrt{1-\rho^{2}}} \exp \left\{-\frac{1}{2\left(1-\rho^{2}\right.}\left[\left(\frac{\mathrm{x}-\mu_{\mathrm{i}}}{\sigma_{\mathrm{i}}}\right)^{2}-2 \rho\left(\frac{\mathrm{x}-\mu_{\mathrm{i}}}{\sigma_{\mathrm{i}}}\right)\left(\frac{\mathrm{y}-\mu_{\mathrm{j}}}{\sigma_{\mathrm{j}}}\right)+\left(\frac{\mathrm{y}-\mu_{\mathrm{i}}}{\sigma_{\mathrm{j}}}\right)^{2}\right]\right\} \mathrm{dxdy}
\end{aligned}
$$

Where $-\infty \leq x \leq K_{i},-\infty \leq y \leq K_{j}$.

Generally, $-\infty \leq x \leq \infty,-\infty \leq y \leq \infty$.
We shall approximate this integral by a Visual Basic program in Excel. This is illustrated in the Figure 1.

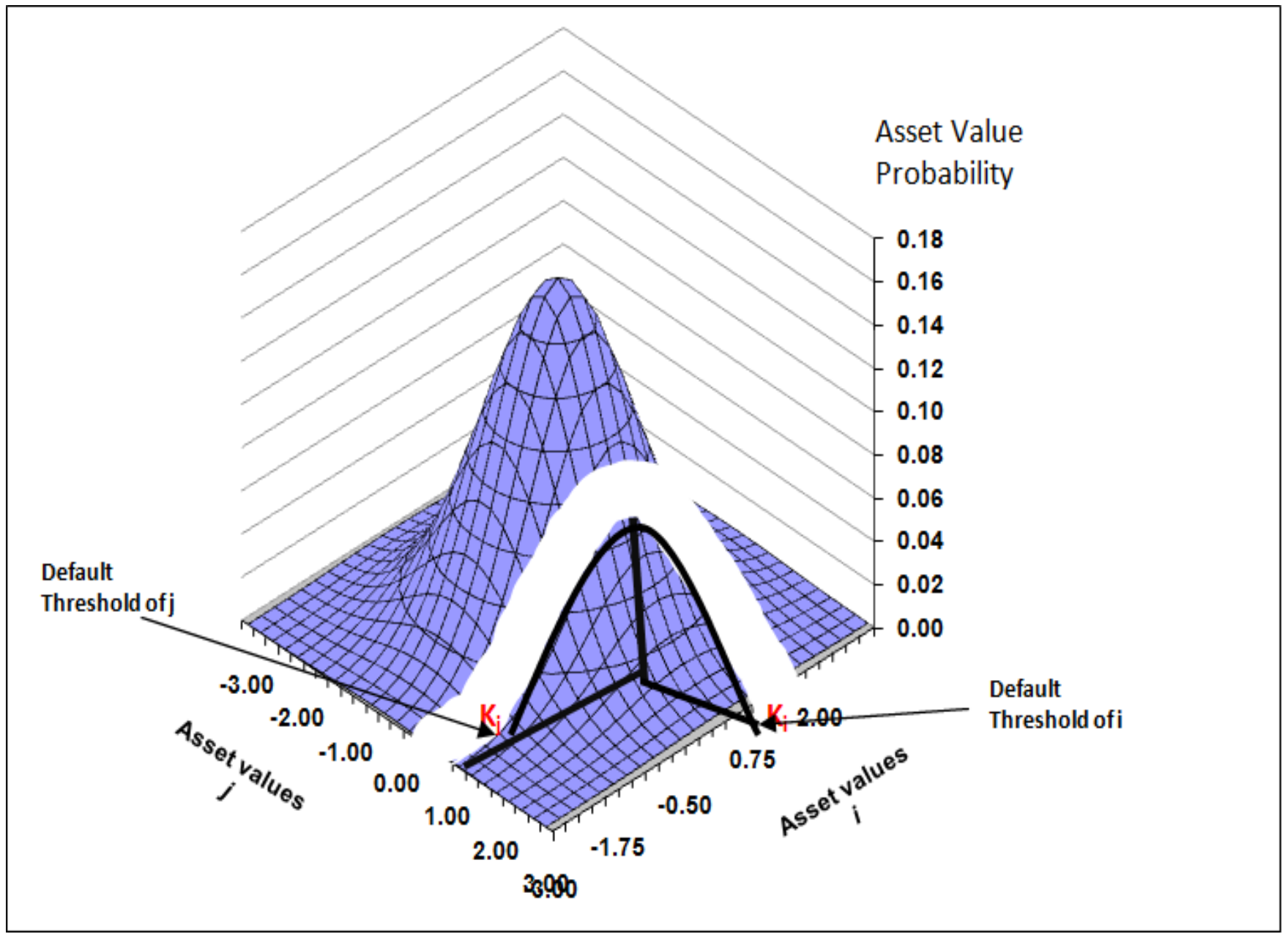

Figure 1. Asset value threshold of obligor $i$ and obligor $j$.

Figure 1 shows the asset values of obligor $i$ and obligor $j$. The default threshold is the white line running from left to right. $K_{i}$ and $K_{j}$ are the default points of obligor $i$ and obligor $j$. If the asset values of an obligor falls below the obligor's default threshold, the obligor defaults.

To estimate the JDP we need to establish the volume under the asset value probability distribution of the two obligors where their assets are less than their default thresholds. To do this we proceed as follows:

- Draw random numbers $(0,1)$ for the two obligors, obligor $i$ and obligor $j$. The random number values generated $(0,1)$ are not normally distributed but the inverse (NORMSINVRAND ( )) is standard normally 
distributed.

- Set the default thresholds of obligor $i$ and obligor $j$. The default thresholds of the obligors are given by $K_{i}=\Phi^{-1}\left(P_{i}\right)$ and $K_{j}=\Phi^{-1}\left(P_{j}\right)$.

- Specify the asset correlation $\rho^{a s s e t_{i, j}}$ between obligor $i$ and obligor $j$ where $0 \leq \rho^{\text {asset }_{i, j}} \leq 1$

- Simulate the model to generate Joint Default Probability of obligor $i$ and obligor $j$. The Joint Default Probability is a function of the PD's of the obligors and their asset correlation $J D P=J D P\left(P_{i}, P_{j}, \rho^{a s s e t_{i, j}}\right)$
By simulating in Excel we can obtain the JDPs for a given default probability for obligor $i$ and obligor $j$.

To do this we set the following parameters.

Default Probability of Obligor $i=2 \%$

Default Probability of Obligor $j=3 \%$

Asset Correlation i, $\mathrm{j}=\rho^{\text {asset }_{i, j}}=8 \%$

\section{Results and Discussion}

The results of the Joint Default Probability for the asset value obligor $i$ and asset value obligor $j$ is shown in Table 1 .

Table 1. Joint Default Probability of obligor i and obligor $j$

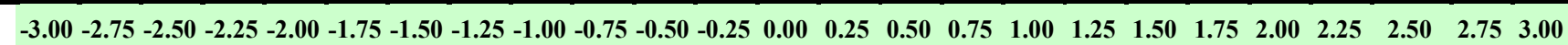
$\begin{array}{llllllllllllllllllllllllllllll}\mathbf{- 3 . 0 0} & 0.00 & 0.00 & 0.00 & 0.00 & 0.00 & 0.00 & 0.00 & 0.00 & 0.00 & 0.00 & 0.00 & 0.00 & 0.00 & 0.00 & 0.00 & 0.00 & 0.00 & 0.00 & 0.00 & 0.00 & 0.00 & 0.00 & 0.00 & 0.00 & 0.00\end{array}$

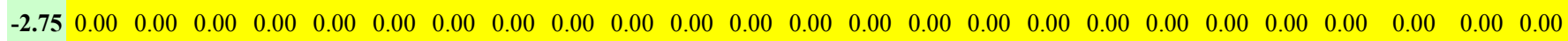
$\begin{array}{llllllllllllllllllllllllll}\mathbf{- 2 . 5 0} & 0.00 & 0.00 & 0.00 & 0.00 & 0.00 & 0.00 & 0.00 & 0.00 & 0.00 & 0.01 & 0.01 & 0.01 & 0.01 & 0.01 & 0.01 & 0.00 & 0.00 & 0.00 & 0.00 & 0.00 & 0.00 & 0.00 & 0.00 & 0.00 & 0.00\end{array}$ $\begin{array}{llllllllllllllllllllllllll}\mathbf{- 2 . 2 5} & 0.00 & 0.00 & 0.00 & 0.00 & 0.00 & 0.00 & 0.00 & 0.01 & 0.01 & 0.01 & 0.01 & 0.01 & 0.01 & 0.01 & 0.01 & 0.01 & 0.01 & 0.01 & 0.00 & 0.00 & 0.00 & 0.00 & 0.00 & 0.00 & 0.00\end{array}$

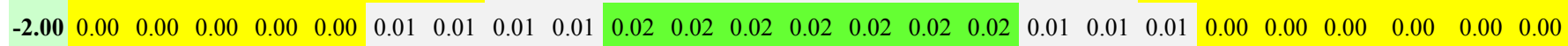
$\begin{array}{llllllllllllllllllllllllllllll}\mathbf{- 1 . 7 5} & 0.00 & 0.00 & 0.00 & 0.00 & 0.01 & 0.01 & 0.01 & 0.02 & 0.02 & 0.03 & 0.03 & 0.03 & 0.03 & 0.03 & 0.03 & 0.02 & 0.02 & 0.01 & 0.01 & 0.01 & 0.00 & 0.00 & 0.00 & 0.00 & 0.00\end{array}$

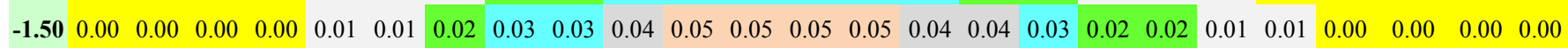

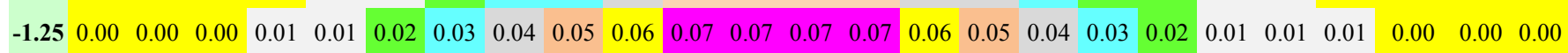
$\begin{array}{llllllllllllllllllllllllllllll}\mathbf{- 1 . 0 0} & 0.00 & 0.00 & 0.00 & 0.01 & 0.01 & 0.02 & 0.03 & 0.05 & 0.06 & 0.08 & 0.09 & 0.09 & 0.10 & 0.09 & 0.08 & 0.07 & 0.06 & 0.04 & 0.03 & 0.02 & 0.01 & 0.01 & 0.00 & 0.00 & 0.00\end{array}$

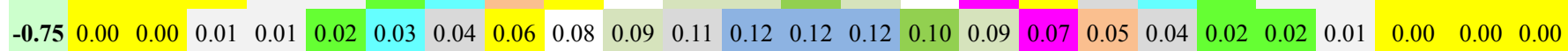
$\begin{array}{lllllllllllllllllllllllllllllll}\mathbf{- 0 . 5 0} & 0.00 & 0.00 & 0.01 & 0.01 & 0.02 & 0.03 & 0.05 & 0.07 & 0.09 & 0.11 & 0.13 & 0.14 & 0.14 & 0.14 & 0.12 & 0.10 & 0.08 & 0.06 & 0.04 & 0.03 & 0.02 & 0.01 & 0.01 & 0.00 & 0.00\end{array}$ $\begin{array}{llllllllllllllllllllllllllllll}\mathbf{- 0 . 2 5} & 0.00 & 0.00 & 0.01 & 0.01 & 0.02 & 0.03 & 0.05 & 0.07 & 0.09 & 0.12 & 0.14 & 0.15 & 0.15 & 0.15 & 0.14 & 0.12 & 0.09 & 0.07 & 0.05 & 0.03 & 0.02 & 0.01 & 0.01 & 0.00 & 0.00\end{array}$

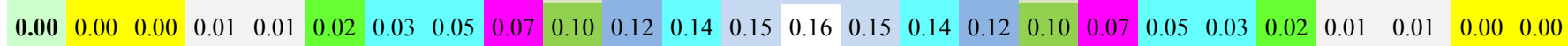
$\begin{array}{llllllllllllllllllllllllllllll}\mathbf{0 . 2 5} & 0.00 & 0.00 & 0.01 & 0.01 & 0.02 & 0.03 & 0.05 & 0.07 & 0.09 & 0.12 & 0.14 & 0.15 & 0.15 & 0.15 & 0.14 & 0.12 & 0.09 & 0.07 & 0.05 & 0.03 & 0.02 & 0.01 & 0.01 & 0.00 & 0.00\end{array}$

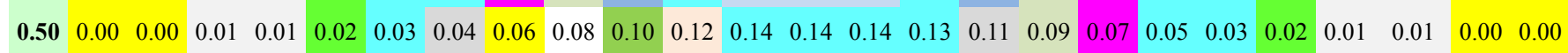
$\begin{array}{lllllllllllllllllllllllllllllllll}\mathbf{0 . 7 5} & 0.00 & 0.00 & 0.00 & 0.01 & 0.02 & 0.02 & 0.04 & 0.05 & 0.07 & 0.09 & 0.10 & 0.12 & 0.12 & 0.12 & 0.11 & 0.09 & 0.08 & 0.06 & 0.04 & 0.03 & 0.02 & 0.01 & 0.01 & 0.00 & 0.00\end{array}$ $\begin{array}{llllllllllllllllllllllllllllll}1.00 & 0.00 & 0.00 & 0.00 & 0.01 & 0.01 & 0.02 & 0.03 & 0.04 & 0.06 & 0.07 & 0.08 & 0.09 & 0.10 & 0.09 & 0.09 & 0.08 & 0.06 & 0.05 & 0.03 & 0.02 & 0.01 & 0.01 & 0.00 & 0.00 & 0.00\end{array}$

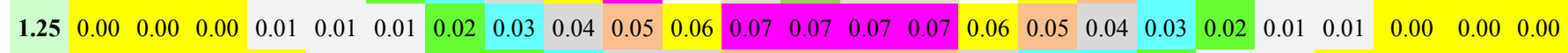
$\begin{array}{llllllllllllllllllllllllllllll}1.50 & 0.00 & 0.00 & 0.00 & 0.00 & 0.01 & 0.01 & 0.02 & 0.02 & 0.03 & 0.04 & 0.04 & 0.05 & 0.05 & 0.05 & 0.05 & 0.04 & 0.03 & 0.03 & 0.02 & 0.01 & 0.01 & 0.00 & 0.00 & 0.00 & 0.00\end{array}$ $\begin{array}{lllllllllllllllllllllllllllllll}1.75 & 0.00 & 0.00 & 0.00 & 0.00 & 0.00 & 0.01 & 0.01 & 0.01 & 0.02 & 0.02 & 0.03 & 0.03 & 0.03 & 0.03 & 0.03 & 0.03 & 0.02 & 0.02 & 0.01 & 0.01 & 0.01 & 0.00 & 0.00 & 0.00 & 0.00\end{array}$

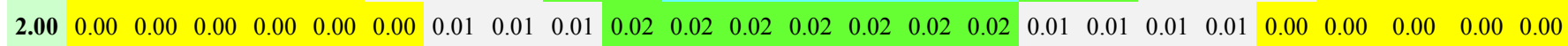

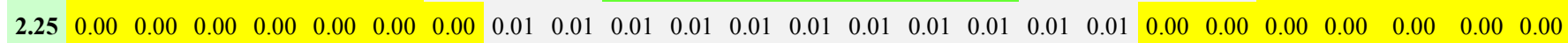

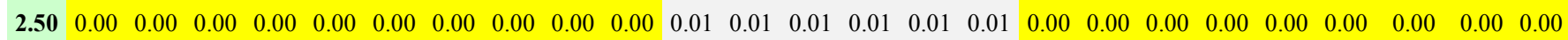
$\begin{array}{llllllllllllllllllllllllllll}2.75 & 0.00 & 0.00 & 0.00 & 0.00 & 0.00 & 0.00 & 0.00 & 0.00 & 0.00 & 0.00 & 0.00 & 0.00 & 0.00 & 0.00 & 0.00 & 0.00 & 0.00 & 0.00 & 0.00 & 0.00 & 0.00 & 0.00 & 0.00 & 0.00 & 0.00\end{array}$ $\begin{array}{lllllllllllllllllllllllllll}3.00 & 0.00 & 0.00 & 0.00 & 0.00 & 0.00 & 0.00 & 0.00 & 0.00 & 0.00 & 0.00 & 0.00 & 0.00 & 0.00 & 0.00 & 0.00 & 0.00 & 0.00 & 0.00 & 0.00 & 0.00 & 0.00 & 0.00 & 0.00 & 0.00 & 0.00\end{array}$
\end{abstract}

Fig 1.1 shows a cross section of the distribution of results for the joint default probability for asset values $i$ and $j$. The distribution of joint default probability shows that:

$$
0 \leq J D P \leq 0.16 \text {. }
$$

As expected, the values of JDP are distributed symmetrically about a centre. This follows from the fact that the asset values were generated from the Gaussian distribution which is symmetric about the mean.
We will now proceed to determine the default correlation by specifying

Probability of Default of Obligor $i=2 \%$

Probability of Default of Obligor $j=3 \%$

If the Joint Default Probability between obligor $i$ and obligor $j=0.08 \%$ 


$$
\begin{aligned}
\rho_{\mathrm{ij}} & =\frac{\mathrm{p}_{\mathrm{ij}}-\mathrm{p}_{\mathrm{i}} \mathrm{p}_{\mathrm{j}}}{\sqrt{\mathrm{p}_{\mathrm{i}}\left(1-\mathrm{p}_{\mathrm{i}}\right) \times \mathrm{p}_{\mathrm{j}}\left(1-\mathrm{p}_{\mathrm{j}}\right)}} \\
\text { Then default correlation }=\rho_{\mathrm{ij}} & =\frac{0.0008-0.02 \times 0.03}{\sqrt{0.02(1-0.02) \times 0.03(1-0.03)}} \\
\rho_{\mathrm{ij}} & =0.008374 \\
\rho_{\mathrm{ij}} & =0.837 \%
\end{aligned}
$$

\section{Conclusions}

We have provided a model that simplifies the mathematical routes to the computation of default correlations under varying macro-economic scenarios. By generating random values to simulate possible asset value processes, we address a critical setback in Merton's model regarding tracking and calibrating asset processes and using that to estimate a critical credit risk component-default correlation. By providing the Excel outputs, we are able to compute default correlations at different asset value levels. This makes it possible to estimate portfolio risk for a range of asset values. All that is required is the standardisation of the asset values which does not involve any extensive mathematical rigour. The approach here is simple to implement in Excel and does not require the analytically complex and computationally intensive formulations that characterises most of the structural approaches in determining default correlation. Further studies can be done in using real asset values (if it's possible to track them) or employing a proxy (usually stock prices) for the asset values. We believe our discussion will provide a constructive alternate approach for analysts that incorporates default correlation their daily credit risk management.

\section{References}

[1] Bank for International Settlements, The New Basel Capital Accord, Consultative Document Basel Committee on Banking Supervision, pp. 84, May 2001.

[2] Black, F. and Scholes, M., "The Pricing of Options and Corporate Liabilities.” Journal of Political Economy, Vol. 81, pp.637-654, 1973.

[3] Merton R C, On the pricing of corporate debt: the risk structure of interest Rates, Journal of Finance, Vol. 29, pp. 449-70, 1974
[4] Jarrow, R. and Turnbull, S., "Credit Risk: Drawing the Analogy,” Risk Magazine, Vol. 5, No.9, 1992.

[5] Jarrow, R. and Turnbull, S. "Pricing Derivatives on Financial Securities Subject to Credit Risk, Journal of Finance, Vol. 50, No.1, pp. 53-85, 1995.

[6] Duffie, D. and Singleton, K, "Modeling Term Structures of Defaultable Bonds, Review of Financial Studies, Vol. 12, No.4, pp. 197-226, 1999.

[7] Bielecki, T. and Rutkowski, M. Credit Risk: Modeling, Valuation and Hedging. New York, Springer-Verlag, 2002.

[8] Rogers, L. C. G., "Modelling Credit Risk." Working Paper, University of Bath, 1999.

[9] Lando, D., Credit Risk Modeling: Theory and Applications, Princeton University Press, NJ, 2003.

[10] Jarrow, R., vanDeventer, D., andWang, X. "A Robust Test of Merton's Structural Model for Credit Risk Journal of Risk, Vol.6, No.1, pp. 39-58, 2003.

[11] Suresh Sundaresan, A Review of Merton's Model of the Firm's Capital Structure with its Wide Applications Finance \& Economics Division, Columbia Business School, Columbia University, The Annual Review of Financial Economics, Vol. 5, pp. 5.1-5.21. 2013.

[12] Robert A. Jarrow, and Philip Protter, Structural Versus Reduced Form Models: A New Information Based Perspective, Journal of Investment Management, Vol. 2, No. 2, 2004.

[13] Navneet Arora, J.R. Bohn, and F. Zhu. Reduced Form vs. Structural Models of credit risk: A Case Study of three Models, Journal of Investment Management, Vol. 3 No. 4 pp. 43, 2005.

[14] Douglas J. Lucas, Default Correlation and Credit Analysis, the Journal of Fixed Income, Vol. 4, No. 4, pp. 76-87, 1995.

[15] Stefan Huschens, Konstantin Vogl, Robert Wania, Estimation of Default Probabilities and Default Correlations, pp. 239-258, 2005.

[16] Krishan Nagpal and Reza Bahar, Measuring default correlation, Risk magazine, Vol. 14, No. 3, pp. 129-132, March 2001.

[17] G. Loffler, P. N. Posch, Credit Risk Modeling using Excel and VBA, John Wiley \& Sons, Chichester, England, 2007.

[18] Morten Virenfeldt, Deriving Obligor Default Correlations Using Factor Modelling, www.tools4risk.com, July 27, 2010.

[19] Equation Editor, Microsoft word 2010 